\title{
BMJ Open Intermittent pneumatic compression for venous thromboembolism prevention: a systematic review on factors affecting adherence
}

\author{
Richard Greenall (D) , ${ }^{1}$ Rachel E Davis ${ }^{2}$
}

To cite: Greenall R, Davis RE. Intermittent pneumatic compression for venous thromboembolism prevention: a systematic review on factors affecting adherence. BMJ Open 2020;10:e037036. doi:10.1136/ bmjopen-2020-037036

- Prepublication history and additional material for this paper are available online. To view please visit the journal (http:// dx.doi.org/10.1136/bmjopen2020-037036).

Received 20 January 2020

Revised 15 June 2020

Accepted 23 July 2020
D) Check for updates

(c) Author(s) (or their employer(s)) 2020. Re-use permitted under CC BY-NC. No commercial re-use. See rights and permissions. Published by BMJ.

${ }^{1}$ Executive Offices, Princess Royal University Hospital, King's College Hospital NHS Foundation Trust, Farnborough, UK ${ }^{2}$ Centre for Implementation Science, Health Services and Population Research Department, Institute of Psychiatry, Psychology and Neuroscience, King's College London, London, UK

Correspondence to Richard Greenall; writetorichg@gmail.com

\section{ABSTRACT}

Objective Venous thromboembolism (VTE) is a potentially fatal complication of hospitalisation. Intermittent pneumatic compression (IPC) is one approach to reducing the likelihood of a VTE. Adherence to IPC is known to be inadequate though the reasons for this remain unclear. This systematic review explores factors that affect adherence to IPC in the inpatient context.

Methods Information sources-EMBASE, MEDLINE and PsycINFO were searched for literature between January 1960 and May 2019. Eligibility criteria-studies were included if they focused on inpatient care and examined factors affecting adherence to IPC devices.

Results Included studies-a total of 20 out of 1476 studies were included. Synthesis of results-eight factors were identified that affected adherence: patient discomfort $(n=8)$, healthcare professionals' knowledge and behaviours $(n=6)$, mobilisation $(n=6)$, equipment supply and demand $(n=3)$, the use of guidelines $(n=3)$, intensive care context $(n=2)$, computer-assisted prescribing $(n=2)$ and patients' knowledge of IPC $(n=1)$.

Conclusion Overall while the evidence base is quite limited, a number of factors were shown to affect adherence to IPC. These findings could be used to inform future research and quality improvement efforts to increase adherence in this very important, but currently under-researched area.

\section{BACKGROUND}

Venous thromboembolism (VTE) is a term that most commonly refers to deep vein thrombosis (DVT) and pulmonary embolism (PE). VTE affects one in 1000 people annually $^{1}$ and in England in 2018 VTE was recorded as a cause of death in 12000 cases. $^{2}$ Compared with baseline risk, hospitalisation has been correlated with an eightfold increased risk of VTE in medical admissions and a 21-fold increased risk in surgical admissions $^{3}$ with one study estimating that up to $50 \%$ of 625 cases of VTE in the community were related to hospitalisation. ${ }^{4}$ Secondary to adverse drug events, VTE is the leading complication of hospitalisation worldwide. ${ }^{5}$
Strengths and limitations of this study

First known review of the evidence affecting adherence to intermittent pneumatic compression (IPC).

- Eight factors were identified that resulted in measurable changes to adherence to IPC.

- Results largely based on direct observation rather than self-report.

- Studies generally had low sample sizes.

- Studies with different aims and methodologies were included.

The financial cost of hospital-associated VTE is high. In 2017, a UK survey revealed the average cost of treating VTE was $£ 938357$ for each local National Health Service (NHS) region. ${ }^{6}$ At a patient level, a review ${ }^{7}$ identified an increase in cost of $\$ 14000$ for initial diagnosis and the first year of treatment for those with VTE compared with non-VTE affected patients. VTE can have a significant impact on a person's psychosocial well-being with research to suggest that it can be a traumatic, life-changing event which can lead to posttraumatic stress disorder. ${ }^{89}$

Since hospitalisation increases the risk of VTE, it is important to consider if anything can be done to reduce the risk within this context. In England, the national VTE prevention programme combined a mandate for assessment of patient's risk on admission to hospital with best practice prevention guidelines. Early results indicate that its efforts have led to reduced morbidity and mortality. ${ }^{10}$ Similar efforts have been made in the USA ${ }^{11}$ and throughout Europe, recent evidence indicates that better management of the risk of VTE has reduced VTE-related mortality from 12.8 to 6.5 deaths per 100 $000 .^{12}$

Risk assessing all patients on admission to hospital leads to identification of patients at high risk who need thromboprophylaxis (ie, 
treatments to prevent VTE). In the UK, national guidelines ${ }^{13}$ advise using the chemical thromboprophylaxis low molecular weight heparin for most groups of at-risk hospitalised patients. Mechanical thromboprophylaxis is advised for most surgical patients and other high-risk groups, such as patients with stroke. Graduated compression stockings (GCS) are one type of mechanical intervention. GCS exerts graded pressure around the legs, increasing the speed of blood flow and reducing the opportunity for VTE to form. ${ }^{14}$

Intermittent pneumatic compression (IPC) is another type of mechanical device. Fabric sleeves that wrap around a patient's legs are attached to a pump using a tube and are periodically inflated and deflated. IPC is thought to reduce VTE by increasing the speed of blood flow and reducing hypercoagulability through the IPC action stimulating the vessel walls fibrinolytic activity. ${ }^{16}$ Evidence demonstrates that combining IPC and GCS decreases the incidence of VTE to a greater effect than either separately. ${ }^{17}$ Systematic reviews found the same increased effect when combining IPC and pharmacological prophy$\operatorname{laxis}^{18}$ and that IPC can reduce the incidence of VTE in surgical patients. ${ }^{19}$ However, despite these benefits, research has shown considerable variability in adherence to IPC device use, with a systematic review of seven studies in acute hospitals reporting a median adherence rate of $78 \%$ (range $40 \%-89 \%$ ). ${ }^{20}$ The authors concluded that strategies to improve adherence are needed but the question remains as to why non-adherence occurs.

While factors affecting adherence have been reviewed within surgical specialities, ${ }^{19}$ to the best of our knowledge, no attempt has been made to comprehensively investigate the factors that could facilitate or impede adherence to IPC across all specialities. This paper aims to address this important gap in the evidence base by systematically reviewing the factors that influence adherence to IPC for VTE prevention in acute care. Gaining this understanding is critical in order to develop interventions, strategies and policies that are accurately targeted at meeting the challenges of improving adherence. ${ }^{21}$

\section{METHODS}

Patient and public involvement

No patient was involved.

\section{Search strategy}

EMBASE, MEDLINE and PsycINFO were searched for relevant literature published between January 1960 and May 2019. The search strategy comprised terms relating to: (1) population (eg, 'IPC'); (2) intervention (eg, 'strategies') and (3) outcomes (eg, 'adherence'). The search was customised to each database and restricted to titles and abstracts to tighten its specificity. A sensitivity analysis was performed to ensure that the search results included key articles identified through an initial scoping review. Forward and backward citation searching and hand searching of key journals were performed to minimise the likelihood of missing relevant papers. The final search was conducted on 30 May 2019 (for the full search strategy please refer to online supplementary file 1 ).

\section{Inclusion criteria}

Based on UK national guidelines that were current at the time of this review's development (January 2018), ${ }^{13}$ the definition of IPC in this review includes only devices that are applied to the legs and excludes foot compression devices. The first stage of screening (title and abstract) was intentionally inclusive and retained any empirical articles that mentioned adherence to IPC in any context. In the second stage (full text), tighter restrictions applied. Articles were included if they reported barriers or facilitators to adherence to IPC in the inpatient context and included a measure of the effect (percentage change in adherence to IPC) of such factors on adherence (either as a primary or secondary aim or an indirect finding in the results). Dissertations and doctoral theses, books, book reviews, conference posters and presentations, editorials and commentaries were excluded, as were articles not published in English or those focused on patients under 18 years of age. Review/commentary papers that addressed adherence to IPC $^{20}$ were examined for relevant empirical papers but the reviews themselves were excluded.

\section{Study selection and data extraction}

Articles were screened for relevance by the lead author (RG). The second author (RED) screened $20 \%$ of the articles at abstract stage and $100 \%$ at full-text stage. Discrepancies were resolved through joint discussion between the authors. Dual data extraction of the included articles was conducted independently by both authors and then checked for consistency. We did not predetermine the factors that could affect adherence to IPC. Rather, we reviewed the data in each article and then grouped these into categories of factors that could affect adherence to IPC. These factors were decided initially by the first author (RG) and then checked by the second author (RED). Disagreements were resolved by joint discussion until consensus was reached.

\section{Quality assessment}

While numerous scales are available to assess the methodological quality of studies, these are often restricted to specific study designs, including randomised controlled trials (RCTs ${ }^{22}$; case-control and cohort studies ${ }^{23}$ and qualitative studies. ${ }^{24}$ Given our review included articles that employed heterogeneous study designs and differing aims, we did not use a quality assessment scale, nor did we deem this meaningful. We did, however, consider differences in the methodologies that could potentially bias the findings to enable greater understanding of the relative strengths and weaknesses of the research. To gain a comprehensive understanding of the full body of evidence, we did not exclude articles based on their methodological quality. 


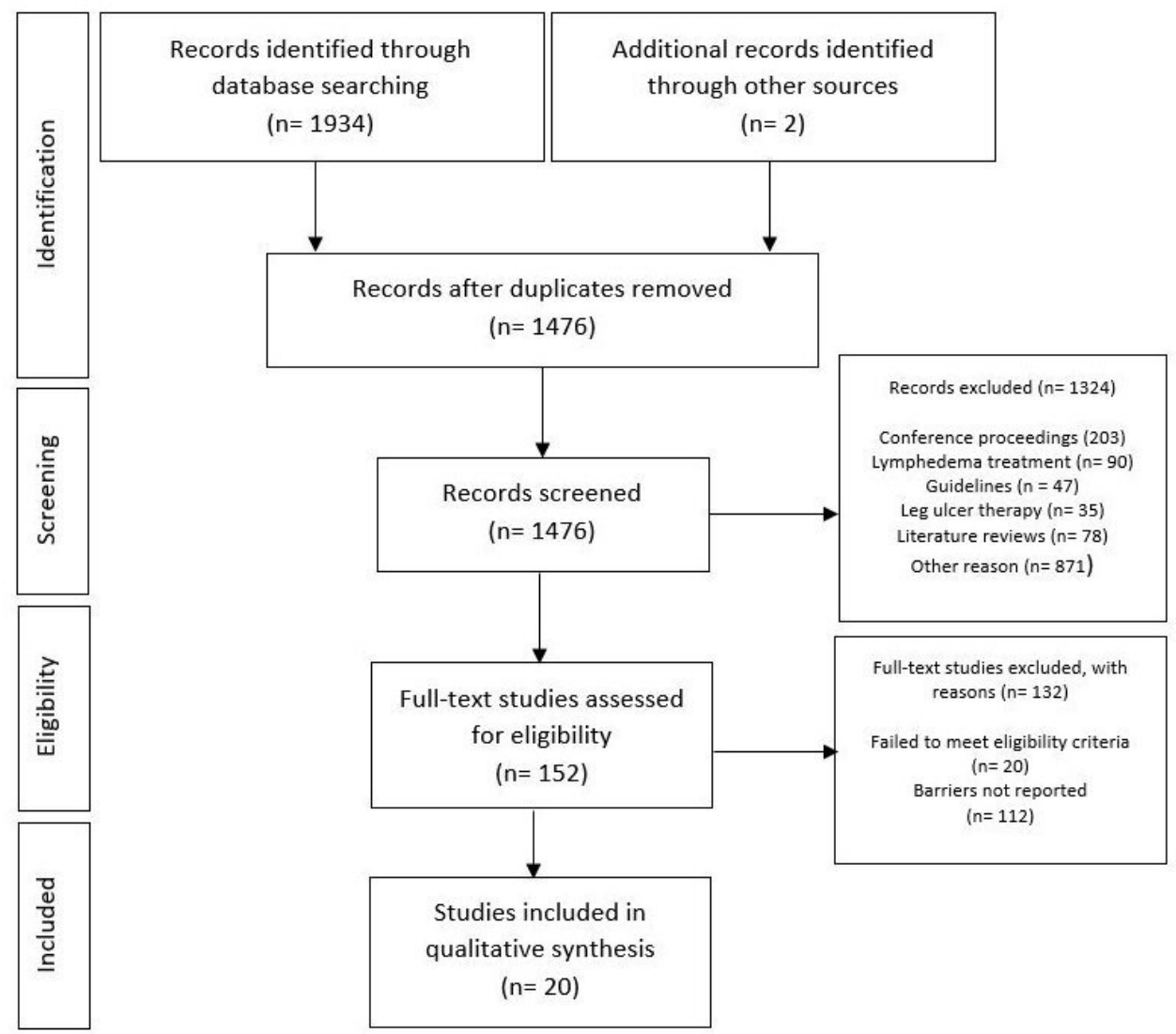

Figure 1 Preferred reporting items for systematic reviews and meta-analyses flowchart of search results retrieved on 30 May 2019.

\section{RESULTS}

\section{Study selection}

Of 1476 articles retrieved, 1324 were excluded at the first stage of screening (title/abstract) and 132 (out of the remaining 152) were excluded after full-text screening, resulting in 20 articles. Two of the included articles were added through handsearching $^{2526}$ (see figure 1). On examination, these studies were missed in the initial search due to the use of the word 'external' instead of 'intermittent' to describe pneumatic compression. Further scoping the literature (using the term 'external') revealed there were no other additional articles that needed to be included.

\section{Characteristics of included studies}

Articles were published between 1992 and 2018 across six countries, including the USA $\left(n=15^{25-39}\right)$, Spain $\left(n=1^{40}\right)$, Japan $\left(n=1^{41}\right)$, Canada $\left(n=1^{42}\right)$, France $\left(n=1^{17}\right)$ and Brazil $\left(n=1^{43}\right)$. Characteristics of patients and care locations included critical care, ${ }^{172629} 4041$ general surgical wards ${ }^{28} \quad 33-35 \quad 384243$ and gynaecology 25 36 $37 \quad 39$ specialties. Factors affecting adherence to IPC was the primary focus of 13 studies. ${ }^{2527-3436373940}$ A further seven studies $^{1726353841-43}$ focused on IPC device safety and effectiveness in preventing VTE but also reported barriers or facilitators to IPC adherence. Seventeen of the studies were observational, ${ }^{26-41} 43$ using surveys and clinical observations as investigation tools. The remaining three studies were RCTs. $^{17} 2542$ Due to wide heterogeneity in study methodologies, meta-analysis was not possible. Table 1 details the characteristics of the included studies.

\section{FACTORS AFFECTING ADHERENCE TO IPC}

Articles varied considerably in the level of content and detail provided regarding study designs and adherence to IPC. We report the main findings here and provide a more detailed analysis of findings for studies where this was possible. Table 2 outlines the eight factors that were identified that affected adherence to IPC.

\section{Patient discomfort}

Patient discomfort associated with wearing the IPC device

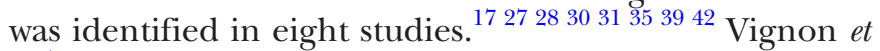
$a l^{17}$ identified poor adherence in 7\% (14/204) of patients due to discomfort, noise and restlessness. Brady et $a l^{30}$ observed the effect of the length of the IPC sleeve on comfort and subsequent non-adherence. Overall adherence was $29 \%$ (40/137) based on a one-off observation. Eighty-five per cent of non-adherent users had been wearing thigh length (53\%) or knee length $(32 \%)$ sleeves. Discomfort was reported as a reason for non-adherence by $39 \%(58 / 149)$ of patients who were non-adherent. Those wearing thigh length sleeves reported double the number of complaints compared with those wearing knee length sleeves (39 vs 15). 


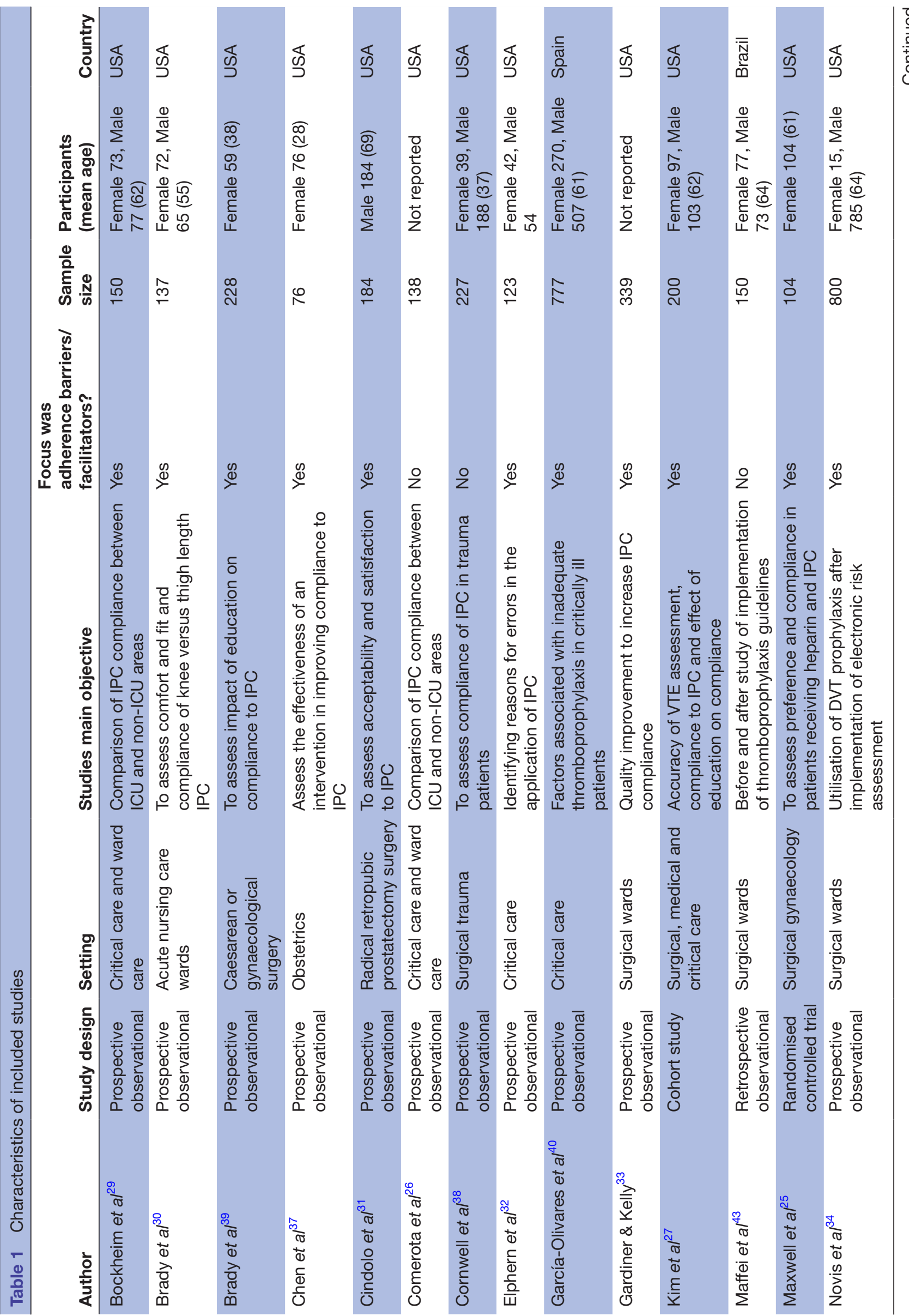


Brady et $a l^{39}$ examined adherence over several days postoperatively. Taking multiple observations of the same patients, adherence was $75 \%(43 / 57)$ on day 0 , $53 \%(148 / 278)$ on day 2 and $44 \%(11 / 25)$ on day 4. Patients who were non-adherent were asked why at the time of observation and 15\% (53/362 responses) stated discomfort as a reason. Kim $e t a l^{27}$ compared two groups of 100 patients in a multifaceted improvement strategy to increase adherence to IPC. Post intervention a slight improvement was achieved (24\% vs $26 \%$ ). Ninety-two per cent (58/63) of nurses and 29\% (4/14) of non-adherent patients reported discomfort as a reason for the lack of adherence.

Ritsema $e t a l^{28}$ found that patients were non-adherent $21 \%$ of the time (98/457 observations) with patient interviews indicating that discomfort was a reason in $19 \%$ $(19 / 100)$ of responses. Sobieraj-Teague $e t a t^{2}$ trialled the efficacy of a newly developed IPC machine which allowed the patient to mobilise independently of a power cable through the utilisation of batteries and small product design. Poor adherence was found in 49\% (35/72) of users, in particular at night, with patients reported they discontinued therapy due to insomnia. Similar findings, but to a much lesser extent, were reported by Cindolo et $a \hat{l}^{31}$ when evaluating the comfort and tolerability of a specific IPC device. While non-adherence was only $3 \%$ (6/184), patients who requested discontinuation of IPC therapy did so due to noise and insomnia.

A final study by Obi $e t a l^{35}$ was designed as a retrospective review examining whether a different design of IPC device would reduce non-adherence. Comparing a standard machine to a new machine, adherence to the standard machine was $47 \%$ vs $85 \%$ for the newer machine. Of responses from those patients wearing the standard compared with the new machine (21 and 24, respectively), problems with discomfort as reported less (33\% vs 13\%).

\section{Healthcare professional (HCP) knowledge and behaviours}

Failure of healthcare professionals to apply or provide IPC when prescribed was identified in six studies. ${ }^{25} 3032333839$ Brady $e t a l^{30}$ found that $16 \%$ (12/73) of survey respondents reported that the nurse had never initiated IPC therapy or had not replaced the sleeves after transfer of the patient from another location. Brady et $a l^{39}$ found that $23 \%(82 / 356)$ of non-adherent patients stated the nurse had informed them that they did not require IPC anymore.

Cornwell et $a l^{38}$ observed adherence of $53 \%$ (out of $712 / 1343$ observations of 233 patients). The authors reported that this was because the device was "not in place'. The time of day that non-adherence was most frequently noted was in the early afternoon and the authors concluded that it is both healthcare professionals (HCPs) and patients who need to be educated about the importance of wearing IPC as the patient may have been the one who removed it.

Elpern $e t a l^{22}$ reported that errors in the application of IPC therapy were identified in $49 \%$ (477/966) of 
Table 2 Factors affecting adherence

\begin{tabular}{|c|c|c|}
\hline Author & Factors & Findings \\
\hline Bockheim et al ${ }^{29}$ & Intensive care context & ICU has greater compliance than non-ICU \\
\hline \multirow[t]{3}{*}{ Brady et $a l^{30}$} & Patient discomfort & Cause of non-adherence was; $39 \%$ discomfort \\
\hline & Mobilisation & $46 \%$ had just ambulated \\
\hline & $\begin{array}{l}\text { Healthcare professional } \\
\text { knowledge and behaviours }\end{array}$ & $13 \%$ the nurse had not reapplied the IPC after transfer from another unit \\
\hline \multirow[t]{4}{*}{ Brady et al ${ }^{39}$} & $\begin{array}{l}\text { Healthcare professional } \\
\text { knowledge and behaviours }\end{array}$ & When asked, $23 \%$ of patients said nurses instruction to not wear \\
\hline & $\begin{array}{l}\text { Equipment supply and } \\
\text { demand }\end{array}$ & $13 \%$ did not have part of the device in the room \\
\hline & Mobilisation & $\begin{array}{l}17 \% \text { said they had just returned to bed, } 16 \% \text { walking around, } 7 \% \text { just about to } \\
\text { walk around }\end{array}$ \\
\hline & Patient discomfort & $15 \%$ of patients said the IPC was uncomfortable \\
\hline Chen et $a l^{37}$ & $\begin{array}{l}\text { Computer-assisted } \\
\text { prescribing }\end{array}$ & A pre-checked electronic order increased prescribing adherence from $46 \%$ to $77 \%$ \\
\hline Cindolo et $a l^{31}$ & Patient discomfort & $\begin{array}{l}\text { Noise and insomnia were reported as being a negative experience in } 23 \% \text { and } \\
44 \% \text { of cases, respectively. Authors state these issues were reasons why } 3 \% \text { had } \\
\text { IPC removed early }\end{array}$ \\
\hline Comerota et $a^{26}$ & Intensive care context & ICU has greater compliance than non-ICU \\
\hline Cornwell et $a^{38}$ & $\begin{array}{l}\text { Healthcare professional } \\
\text { knowledge and behaviours }\end{array}$ & $\begin{array}{l}\text { Compliance rate of } 53 \% \text {. Information reported about non-compliance was that the } \\
\text { device was not in place }(95 \%)\end{array}$ \\
\hline Elpern et $\left.a\right|^{32}$ & $\begin{array}{l}\text { Healthcare professional } \\
\text { knowledge and behaviours }\end{array}$ & $\begin{array}{l}\text { In } 51 \% \text { of non-adherence observed, IPC sleeves were not correctly applied and } \\
24 \% \text { the machine was not switched on }\end{array}$ \\
\hline \multirow[t]{2}{*}{ García-Olivares et a ${ }^{40}$} & Mobilisation & $\begin{array}{l}\text { Patients with invasive mechanical ventilation and complete bedrest had greater } \\
\text { compliance }\end{array}$ \\
\hline & Guidelines & $\begin{array}{l}\text { use of a protocol and risk scoring system led to decreased risk of inappropriate } \\
\text { VTE prophylaxis }\end{array}$ \\
\hline \multirow[t]{2}{*}{ Gardiner et $a l^{33}$} & $\begin{array}{l}\text { Equipment supply and } \\
\text { demand }\end{array}$ & $\begin{array}{l}\text { In } 38 \% \text { of non-adherent cases the IPC machine was not in the room, locating IPC } \\
\text { machines in rooms resulted in adherence from } 26 \% \text { to } 44 \%\end{array}$ \\
\hline & $\begin{array}{l}\text { Healthcare professional } \\
\text { knowledge and behaviours }\end{array}$ & $\begin{array}{l}\text { A nursing knowledge and beliefs survey yields information about barriers that } \\
\text { nurses bring to the use of IPC }\end{array}$ \\
\hline \multirow[t]{2}{*}{ Kim et $\mathrm{al}^{27}$} & Knowledge & $\begin{array}{l}40 \% \text { overall non-adherence to IPC. Of these, } 40 \% \text { said that no one informed them } \\
\text { they needed to keep IPC on }\end{array}$ \\
\hline & Patient discomfort & $40 \%$ overall non-adherence to IPC, $33 \%$ said this was due to discomfort \\
\hline Maffei et $a /^{43}$ & Guidelines & After guidelines were introduced, IPC prescription increased from $26 \%$ to $32 \%$ \\
\hline Maxwell et $a l^{25}$ & $\begin{array}{l}\text { Healthcare professional } \\
\text { knowledge and behaviours }\end{array}$ & $\begin{array}{l}\text { Of } 736 \text { observations, non-compliance was noted in } 2.7 \% \text { of cases and this was } \\
\text { related to the machine not being switched on }\end{array}$ \\
\hline Novis et $a l^{34}$ & $\begin{array}{l}\text { Computer-assisted } \\
\text { prescribing }\end{array}$ & $\begin{array}{l}\text { Electronic suggestion of thromboprophylaxis increased the use of IPC from } 50 \% \text { to } \\
63 \%\end{array}$ \\
\hline \multirow[t]{3}{*}{ Obi et $a l^{35}$} & Device related & A battery powered device facilitated adherence through enabling mobilisation \\
\hline & Patient discomfort & A new machine design led to fewer reports of patient discomfort ( $33 \%$ vs $13 \%)$ \\
\hline & Mobilisation & Problems with mobilisation were less using a new machine (71\% vs 29\%) \\
\hline Palmerola et $a^{36}$ & Mobilisation & $\begin{array}{l}38 \% \text { of patients classed as non-adherent to IPC therapy had it discontinued due to } \\
\text { liberal standards for ambulation }\end{array}$ \\
\hline \multirow[t]{3}{*}{ Ritsema et $a l^{28}$} & Mobilisation & Not replaced after mobilising accounted for $50 \%$ of non-compliant observations \\
\hline & $\begin{array}{l}\text { Equipment supply and } \\
\text { demand }\end{array}$ & Lack of machine or cuffs accounted for $22 \%$ of non-adherence \\
\hline & Patient discomfort & Patient discomfort accounted for $19 \%$ of non-adherence \\
\hline Sobierag-Teague et al ${ }^{42}$ & Patient discomfort & $\begin{array}{l}48 \% \text { of users discontinued the device at night. Comfort-related issues discussed } \\
\text { but not explicitly linked to non-adherence }\end{array}$ \\
\hline Vignon et $a l^{17}$ & Patient discomfort & $\begin{array}{l}7 \% \text { non-compliance in the AES+IPC group. IPC was discontinued due to } \\
\text { discomfort, noise and restlessness }\end{array}$ \\
\hline Yamamoto et al ${ }^{41}$ & Guidelines & $\begin{array}{l}\text { Combined AES and IPC mechanical prophylaxis was higher in units with a protocol } \\
\text { than without }(88 \% \text { vs } 80 \%)\end{array}$ \\
\hline
\end{tabular}


observations of a cohort of 123 patients. In 244 observations, the sleeves were incorrectly applied to the patient and in 116 observations, the pump was not turned on. Similar findings by Maxwell et $a l^{25}$ in 104 patients identified that the reason for non-adherence in 3\% (20/736) of observations was that the IPC was not turned on. Gardiner et $a l^{33}$ reported that only $26 \%(89 / 339)$ of patients were adherent to IPC on initial audit. A survey of nursing beliefs, practice and knowledge determined that part of the problem was deficiencies in nursing knowledge. Education interventions as well as placing IPC machines in individual rooms of patients improved adherence from $26 \%$ to $44 \%$.

\section{Mobilisation}

Issues relating to mobilisation were identified as factors affecting adherence in six studies. ${ }^{28} 3035363940$ Brady et $a l^{30}$ found that of 149 responses from non-adherent patients, $46 \%(68 / 149)$ of patients reported that they had just mobilised. Similarly, Brady et $a l^{39}$ found that $16 \%(59 / 362)$ of patients reported that they had just been walking around, $17 \%(62 / 362)$ stated they had just returned to bed and 7\% (24/362) were just about to walk around. In a study by Ritsema $e t a l^{28}$ previously discussed in relation to patient discomfort, patients identified that not replacing the IPC sleeves after mobilisation was a cause of non-adherence in 50\% of 98 non-adherent episodes observed.

Palmerola $e t a \hat{l}^{36}$ found adherence to IPC after caesarean delivery was $79.5 \%$ (233/293). Of the 60 non-adherent patients, $62 \%(37 / 60)$ had the IPC machine and sleeves in the room but they were not applied and 38\% (23/60) had it discontinued due to 'liberal standards for mobilisation'. A study by Obi $e t a l^{35}$ previously discussed in relation to 'patient discomfort' found that problems with mobilising were reported less using a new machine compared with a standard one $(71 \%$ vs $29 \%)$. García-Olivares et $a t^{t 0}$ found that complete bed rest for $>2$ days resulted in improved appropriateness of prophylaxis (OR 0.6) with similar findings reported for mechanical ventilation (OR 0.7).

\section{Equipment supply and demand}

Three studies ${ }^{28} 3339$ highlighted that equipment supply and demand could affect adherence. Brady $e t a l^{39}$ identified that part of the IPC device was not present in the room in $13 \%(49 / 362)$ of non-adherent episodes although reasons why were not explored. Similar findings by Ritsema $e t a l^{28}$ found that the second most commonly reported reason for non-adherence was no machine or sleeves being available to the patient (22/100 questionnaire responses). As previously discussed within 'healthcare professionals knowledge and behaviours', a study by Gardiner $e t a l^{33}$ revealed that of 250 patients who were non-adherent, 39\% (97/250) did not have part of the equipment in the room. This same study found that adherence increased from $26 \%$ to $44 \%$ through an educational intervention and making IPC machines widely available instead of difficult to obtain for use.

\section{Guidelines}

The use of guidelines for VTE prevention was identified as a factor that could affect adherence in three studies. ${ }^{40} 4143$ García-Olivares et $a t^{40}$ used an electronic questionnaire to investigate inappropriateness of VTE prophylaxis (all types) on a single day across multiple intensive care units (ICUs). A total of 777 patients across 73 ICUs were included: the use of a protocol reduced inappropriate VTE prevention prescribing (OR 0.6) as well as a VTE risk scoring system (OR 0.4). Yamamoto $e t a l^{41}$ obtained data from 99 ICUs and included 470 patients in their analysis. Hospitals using protocols had higher rates of prophylaxis provision than those who did not $(89 \%$ vs $80 \%)$ and this difference was mainly due to the increase in the combined use of anti-embolic stockings (AES) and IPC (26\% vs $15 \%)$. A similar effect was demonstrated by Maffei $e t a t^{43}$ who retrospectively analysed the accuracy of prescribing of VTE prophylaxis after the implementation of guidelines. Compared with before the implementation of guidelines, prescribing of IPC therapy increased from $26 \%$ to $32 \%$ after.

\section{Intensive care context}

Care provision in the ICU context was identified by two studies as having an impact on adherence. ${ }^{26}{ }^{29}$ Comerota et $a l^{26}$ examined 138 patients and found that adherence in the ICU setting was higher than elsewhere in the hospital (78\% vs $48 \%$ ) but did not investigate reasons for this. A study by Bockheim et $a t^{29}$ found adherence in the ICU context was $69 \%(52 / 75)$ compared with $40 \%(30 / 75)$ outside of the ICU. The authors concluded the reasons for this were likely to be multifactorial they did not empirically determine what these factors might be.

\section{Computer-assisted prescribing}

Computer-assisted prescribing was reported as a factor affecting adherence in two studies. ${ }^{34}{ }^{37}$ Chen $e t a l^{37}$ examined the long-term impact of automatic pre-orders for IPC on an electronic prescription system. Prior to the intervention, prescribing of IPC was carried out on $46 \%$ (denominator not reported) of patients. One year later, this had increased to $78 \%(59 / 76)$. IPC was only present in $71 \%(42 / 59)$ of patients who had been prescribed IPC and was only being used by $45 \%(19 / 42)$ of those patients. The authors concluded that the intervention had successfully increased prescribing of IPC but not overall adherence.

Novis $e$ t $a \hat{l}^{4}$ used a similar approach but did not assess the impact of adherence to IPC at a patient level. Computer-generated suggestions of preoperative prophylaxis were provided to the clinician as a result of information entered about the risk of VTE to the patient. The result was a $40 \%$ increase in prescribing of IPC from 215 to 301 patients with an active prescription.

\section{Patient knowledge}

A study by Kim et $a l^{27}$ concluded that the information needs of patients were a factor affecting adherence. An 
initial survey found that $59 \%(32 / 54)$ of patients did not have IPC applied when prescribed. Several clinicianfocused interventions were conducted, and a survey of patients a year later found that $62 \%(41 / 66)$ of patients requiring IPC therapy did not have it applied. From this, $30 \%(11 / 37)$ of patients reported that they did not know what a DVT is and $62 \%(23 / 37)$ reported that they had not been educated about IPC. The authors conclude that a lack of education is an important barrier to adherence, however, evidence to demonstrate that increasing education results in improved adherence was not presented.

\section{QUALITY ASSESSMENT}

Seventeen ${ }^{26-41} 43$ (out of the 20) articles included in the review were observational in nature. All of these studies $(n=17)$ measured adherence to IPC by direct observation of researchers rather than based on self-report, which could have been subject to recall bias. Eight of these studies measured adherence twice daily, 2526282933373942 three had a single observation point (the first day postoperatively $^{3136}$ and not reported ${ }^{30}$ ), one ${ }^{35}$ had hourly monitoring across a 24 hours period and one ${ }^{17}$ did not report when they observed adherence, only that they did this. In addition to direct observations, data on factors affecting adherence using patient surveys were performed in eight studies ${ }^{1725272830313942}$ and indirect indicators such as the effect of a change in device type or the result of a guideline implementation was used in seven studies. ${ }^{26} 2934353743$ The three RCTs ${ }^{17} 2542$ collected data on adherence using researcher observations and patient surveys.

Over half of the articles ${ }^{25}$ 27-34 $36373940(n=13)$ focused on factors affecting adherence to IPC as a primary outcome. The remaining studies ${ }^{17} 26353841-43 \quad(n=7)$ investigated as the safety and effectiveness of IPC as their main outcome. As a result of these investigations, these studies also provided data on factors affecting adherence (though this was not their aim). It is difficult to determine whether additional factors may have been uncovered from these studies (ie, that are not reported in our findings) if the authors had specifically set out to examine how adherence to IPC could be affected. Taken collectively, the patient sample sizes for each study ranged from between 67 (35) to 800 (34) with the majority of studies being based on over 100 patients. Articles we included were published across a 27-year period.

\section{DISCUSSION}

This paper presents the findings of a systematic review on factors affecting adherence to IPC in the inpatient setting. In total eight factors were identified that affected adherence, with patient discomfort related to wearing the IPC device being most commonly reported and issues related to computer-assisted prescribing and patients' knowledge of IPC being the least frequently reported. The majority of factors delineated (such as patient discomfort, mobilising, healthcare professional knowledge and behaviours, patient knowledge, equipment supply and demand) acted as a barrier to adherence to IPC. However, some evidence points to specific facilitators of adherence (eg, the use of guidelines and protocols and computer-assisted prescribing).

There are several important implications of this work. First, discomfort with the IPC device was a considerable cause for non-adherence. The development and/or use of new or alternative IPC devices should be considered when addressing adherence issues. Research has demonstrated that using methods to systematically incorporate the user perspective early in the design process can result in the development of a device which is safe, effective and used by the patient. ${ }^{44}$ Research more widely in the field that examined the use of a modern IPC device demonstrates that it is possible to develop comfortable devices ${ }^{45}$ with $86 \%(26 / 30)$ of patients reporting it was comfortable and that they would use it again if required. Two studies ${ }^{35} 42$ within this review reported adherence levels when studying different machine designs and one study focused on the length of IPC sleeve ${ }^{30}$ and its effect on adherence with knee length sleeves being adhered to to a greater degree. The same study found similar results with the length of AES and this was also found in a review of adherence in surgical specialities. ${ }^{46}$ There is, therefore, scope for further research using a randomised control study design to assess widely used IPC machines, the length of sleeves and the effect both factors have on adherence, particularly in relation to comfort.

Second, and related to the above point, mobility was often reported as a barrier to adherence. One likely explanation for this could be that it was uncomfortable for patients to mobilise while wearing the device, so for this reason it was removed. Evidence ${ }^{26}{ }^{29}$ from our review revealed that adherence was less of an issue for those patients that were unable to move around. However, IPC is designed to promote blood flow during immobility and if a patient is mobile, it could be concluded that IPC is no longer required and thus would not meet the criteria for data being collected as adherent or not. While this is a point that warrants further investigation, our findings suggest this could be why mobilisation (perhaps wrongly so) was identified as an adherence-related issue. Within the wider literature, a systematic review ${ }^{47}$ on the definition used for immobility within thromboprophylaxis studies concluded that a lack of consistency in the definition of immobility may contribute to the underutilisation of thromboprophylaxis in clinical practice. In our review, the definition of mobility to the extent that IPC was no longer required was not stated by any of our included studies. In place of a widely agreed consensus, an institution-wide definition of mobility could assist individual hospitals to ensure that best practice is promoted in relation to IPC adherence.

Third, we found that HCP knowledge and beliefs could contribute to non-adherence. It is not clear from our studies whether on those occasions when an IPC device was not fitted, the reasons related more to the HCP not 
knowing they needed to do this, whether they simply forget, or whether there has been some other unknown issue. While this warrants further investigations, there are some relatively straightforward strategies that could be put in place, based on our preliminary findings. For example, prompts and educational leaflets could be distributed on the hospital wards to remind HCPs when the use of IPC is required and why this is important. Training is essential if optimal adherence levels are to be achieved and maintained. Equally, ensuring the layout of the ward allows easy accessibility of equipment (such as IPC) is also important, particularly, given our review revealed this to be a determinant of adherence.

Finally, our review revealed that the use of guidelines and how they are incorporated into electronic prescribing systems could act as a facilitator to adherence. Similar findings (which examined, in part the use of pre-printed orders) have been reported in a review of the barriers and facilitators to adherence to chemical thromboprophylaxis ${ }^{48}$ within the ICU setting. Additional research that examined how electronic prescribing can lead to a reduction in errors, identified an absolute risk reduction of up to $30 \% .^{49}$ Together with the evidence in this review, it could be concluded that if IPC prescribing is included in electronic prescribing systems, improvements in adherence to guidelines may be achieved.

\section{STRENGTHS AND LIMITATIONS}

There are several strengths of this review. To the best of our knowledge, this is the only paper of its kind to systematically review the evidence on factors affecting adherence to IPC across medical and surgical specialities. Wider research within the field that has reviewed the literature relating to IPC adherence found a median adherence rate of $78 \% .^{20}$ The review concluded that strategies to improve adherence are required. Our review helps to address this important gap in the evidence, shedding light on potential indicators of issue.

The evidence in our review was derived from articles that provided an actual measure of adherence in clinical settings and the subsequent factors that could help to explain these adherence rates. Many of the factors relating to adherence were based on direct observation rather than self-report.

A caveat to mention when interpreting our findings is that while data were based on quite a large body of evidence, there were differing (and sometimes low) sample sizes as well as different aims and methodologies and countries and settings of focus. Included studies were also spread over a long period of time (27 years), in which policies and procedures around IPC may have changed. Equally most of the factors affecting adherence were only reported a few times. While, admittedly this was not the primary aim of the studies included in our review, but rather was reported as secondary finding in relation to explaining adherence rates, further work is required to understand the relative strength of the evidence.
Nonetheless, this review provides a useful first step to delineating important (and perhaps otherwise empirically unknown) factors affecting adherence to IPC. These findings could be used to help inform, implement and evaluate the use of specific strategies to overcome factors causing adherence-related issues.

\section{CONCLUSION}

This systematic review set out to uncover the factors that affect adherence to IPC for VTE prevention in acute care. Gaining this understanding is critical in order to develop interventions, strategies and policies which are accurately targeted at meeting the challenges of improving adherence. ${ }^{21}$ While our review has addressed an important gap in the evidence base and taken the first steps to understanding reasons why non-adherence to IPC may occur, it is clear more research is required in this area to further understand the relative strength of the evidence, so that effective strategies to overcome barriers to adherence can be sought.

\section{Twitter Richard Greenall @kingsnurserich}

Contributors RG and RED designed the paper and were responsible for its conceptualisation. RG drafted the paper and RED edited it. Both authors were involved in the screening of the articles included in the review and have read and approved the final version of the manuscript.

Funding The authors have not declared a specific grant for this research from any funding agency in the public, commercial or not-for-profit sectors. RED is supported by the National Institute for Health Research (NIHR) Applied Research Collaboration: South London at King's College Hospital NHS Foundation Trust. The views expressed in this publication are those of the author(s) and not necessarily those of the NHS, NIHR, or the Department of Health and Social Care.

Competing interests None declared.

Patient consent for publication Not required.

Provenance and peer review Not commissioned; externally peer reviewed.

Data availability statement All data relevant to the study are included in the article or uploaded as supplementary information. All data generated or analysed during this study are included in this published article (and its supplementary information files)

Open access This is an open access article distributed in accordance with the Creative Commons Attribution Non Commercial (CC BY-NC 4.0) license, which permits others to distribute, remix, adapt, build upon this work non-commercially, and license their derivative works on different terms, provided the original work is properly cited, appropriate credit is given, any changes made indicated, and the use is non-commercial. See: http://creativecommons.org/licenses/by-nc/4.0/.

ORCID iD

Richard Greenall http://orcid.org/0000-0002-8880-7495

\section{REFERENCES}

1 Silverstein MD, Heit JA, Mohr DN, et al. Trends in the incidence of deep vein thrombosis and pulmonary embolism: a 25-year population-based study. Arch Intern Med 1998;158:585-93.

2 NHS Digital. 5.1 deaths from venous thromboembolism (VTe) related events within 90 days post discharge from hospital, 2019. Available: https://digital.nhs.uk/data-and-information/publications/statistical/ nhs-outcomes-framework/august-2020/domain-5-treating-andcaring-for-people-in-a-safe-environment-and-protecting-them-fromavoidable-harm-nof/5-1-deaths-from-venous-thromboembolismvte-related-events-within-90-days-post-discharge-from-hospital [Accessed 18 Oct 2019]. 
3 Heit JA, Silverstein MD, Mohr DN, et al. Risk factors for deep vein thrombosis and pulmonary embolism: a population-based casecontrol study. Arch Intern Med 2000;160:809-15.

4 Heit JA, O'Fallon WM, Petterson TM, et al. Relative impact of risk factors for deep vein thrombosis and pulmonary embolism: a population-based study. Arch Intern Med 2002;162:1245-8.

5 Jha AK, Larizgoitia I, Audera-Lopez C, et al. The global burden of unsafe medical care: Analytic modelling of observational studies. BMJ Qual Saf 2013;22:809-15.

6 All-Party Parliamentary Thrombosis Group. All-Party parliamentary thrombosis group annual review 2017, 2017.

7 Grosse SD, Nelson RE, Nyarko KA, et al. The economic burden of incident venous thromboembolism in the United States: a review of estimated attributable healthcare costs. Thromb Res 2016;137:3-10.

8 Noble S, Lewis R, Whithers J, et al. Long-term psychological consequences of symptomatic pulmonary embolism: a qualitative study. BMJ Open 2014;4:e004561.

9 Hunter R, Lewis S, Noble S, et al. "Post-thrombotic panic syndrome": A thematic analysis of the experience of venous thromboembolism. $\mathrm{Br} J$ Health Psychol 2017;22:8-25.

10 Roberts LN, Durkin M, Arya R. Annotation: developing a national programme for VTe prevention. Br J Haematol 2017;178:162-70.

11 Maynard GA. Preventing hospital-associated venous thromboembolism: a guide for effective quality improvement. 2nd edn. Rockville, MD: Agency for Healthcare Research and Quality, US Department of Health and Human Services, 2015.

12 Barco S, Mahmoudpour SH, Valerio L, et al. Trends in mortality related to pulmonary embolism in the European region, 2000-15 analysis of vital registration data from the WHO mortality database. Lancet Respir Med 2020;8:277-87.

13 NICE. Clinical guideline 92 venous thromboembolism: reducing the risk: reducing the risk of venous thromboembolism (deep vein thrombosis and pulmonary embolism), 2010. Available: https://www. nice.org.uk/guidance/ [Accessed 11 May 2018].

14 Sigel B, Edelstein AL, Savitch L, et al. Type of compression for reducing venous stasis. A study of lower extremities during inactive recumbency. Arch Surg 1975;110:171-5.

15 Jacobs DG, Piotrowski JJ, Hoppensteadt DA, et al. Hemodynamic and fibrinolytic consequences of intermittent pneumatic compression: preliminary results. J Trauma 1996;40:710-7.

16 Comerota AJ, Chouhan V, Harada RN, et al. The fibrinolytic effects of intermittent pneumatic compression: mechanism of enhanced fibrinolysis. Ann Surg 1997;226:306-14.

17 Vignon P, Dequin P-F, Renault A, et al. Intermittent pneumatic compression to prevent venous thromboembolism in patients with high risk of bleeding hospitalized in intensive care units: the CIREA1 randomized trial. Intensive Care Med 2013;39:872-80.

18 Kakkos SK, Caprini JA, Geroulakos G, et al. Combined intermittent pneumatic leg compression and pharmacological prophylaxis for prevention of venous thromboembolism. Cochrane Database Syst Rev 2016;9:CD005258.

19 Pavon JM, Adam SS, Razouki ZA, et al. Effectiveness of intermittent pneumatic compression devices for venous thromboembolism prophylaxis in high-risk surgical patients: a systematic review. $J$ Arthroplasty 2016;31:524-32.

20 Craigie S, Tsui JF, Agarwal A, et al. Adherence to mechanical thromboprophylaxis after surgery: a systematic review and metaanalysis. Thromb Res 2015;136:723-6.

21 World Health Organisation. Adherence to long-term therapies evidence for action. World Health Organisation, 2003.

22 Jadad AR, Moore RA, Carroll D, et al. Assessing the quality of reports of randomized clinical trials: is blinding necessary? Control Clin Trials 1996;17:1-12.

23 Wells G. The Newcastle-Ottawa scale (NOS) for assessing the quality of non randomised studies in meta-analyses, 2001. Available: http:// www.ohri.ca/programs/clinical epidemiology/oxford.asp

24 Blaxter M. Criteria for the evaluation of qualitative research papers. Med Soc News 1996;22:68-71.

25 Maxwell GL, Synan I, Hayes RP, et al. Preference and compliance in postoperative thromboembolism prophylaxis among gynecologic oncology patients. Obstet Gynecol 2002;100:451-5

26 Comerota AJ, Katz ML, White JV. Why does prophylaxis with external pneumatic compression for deep vein thrombosis fail? Am J Surg 1992;164:265-8

27 Kim PS, Probeck K, Elitharp D, et al. The staff and patient perspectives on compliance with mechanical prophylaxis for venous thromboembolism. J Vasc Surg Venous Lymphat Disord 2018;6:441-8.

28 Ritsema DF, Watson JM, Stiteler AP, et al. Sequential compression devices in postoperative urologic patients: an observational trial and survey study on the influence of patient and hospital factors on compliance. BMC Urol 2013;13:20.

29 Bockheim HM, McAllen KJ, Baker R, et al. Mechanical prophylaxis to prevent venous thromboembolism in surgical patients: a prospective trial evaluating compliance. J Crit Care 2009;24:192-6.

30 Brady D, Raingruber B, Peterson J, et al. The use of knee-length versus thigh-length compression stockings and sequential compression devices. Crit Care Nurs Q 2007;30:255-62.

31 Cindolo L, Salzano L, Mirone V, et al. Thromboprophylaxis in radical retropubic prostatectomy: efficacy and patient compliance of a dual modality. Urol Int 2009;83:12-18.

32 Elpern E, Killeen K, Patel G, et al. The application of intermittent pneumatic compression devices for thromboprophylaxis: an observational study found frequent errors in the application of these mechanical devices in ICUs. Am J Nurs 2013;113:30-6.

33 Gardiner DA, Kelly B. Improving rates of intermittent pneumatic compression therapy utilization. Hosp Pract 2013;41:40-7.

34 Novis SJ, Havelka GE, Ostrowski D, et al. Prevention of thromboembolic events in surgical patients through the creation and implementation of a computerized risk assessment program. $J$ Vasc Surg 2010;51:648-54.

35 Obi AT, Alvarez R, Reames BN, et al. A prospective evaluation of standard versus battery-powered sequential compression devices in postsurgical patients. Am J Surg 2015;209:675-81.

36 Palmerola KL, Brock CO, D'Alton ME, et al. Compliance with mechanical venous thromboproembolism prophylaxis after cesarean delivery. J Matern Fetal Neonatal Med 2016;29:3072-5.

37 Chen M, Sarnoski KA, Jacques LH, et al. Sequential compression device compliance in pregnant women requiring antepartum admission. J Matern Fetal Neonatal Med 2019:1-7.

38 Cornwell EE, Chang D, Velmahos G, et al. Compliance with sequential compression device prophylaxis in at-risk trauma patients: a prospective analysis. Am Surg 2002;68:470-3.

39 Brady MA, Carroll AW, Cheang KI, et al. Sequential compression device compliance in postoperative obstetrics and gynecology patients. Obstet Gynecol 2015;125:19-25.

40 García-Olivares P, Guerrero JE, Keough E, et al. Clinical factors associated with inappropriate prophylaxis of venous thromboembolic disease in critically ill patients. A single day cross-sectional study. Thromb Res 2016;143:111-7.

41 Yamamoto T, Nakamura M, Kuroiwa M, et al. Current prevention practice for venous thromboembolism in Japanese intensive care units. J Anesth 2013;27:931-4.

42 Sobieraj-Teague M, Hirsh J, Yip G, et al. Randomized controlled trial of a new portable calf compression device (Venowave) for prevention of venous thrombosis in high-risk neurosurgical patients. J Thromb Haemost 2012;10:229-35.

43 Maffei FHdeA, Sato AC, Torggler Filho F, et al. [Effect of the implementation of a guideline for venous thromboembolism prophylaxis in surgical patients]. Rev Assoc Med Bras 2009;55:587-92.

44 Martin JL, Clark DJ, Morgan SP, et al. A user-centred approach to requirements elicitation in medical device development: a case study from an industry perspective. Appl Ergon 2012;43:184-90.

45 Guimicheva B, Patel JP, Roberts LN, et al. Women's views, adherence and experience with postnatal thromboprophylaxis. Thromb Res 2019;173:85-90.

46 Wade R, Paton F, Woolacott N. Systematic review of patient preference and adherence to the correct use of graduated compression stockings to prevent deep vein thrombosis in surgical patients. J Adv Nurs 2017;73:336-48.

47 Emed JD, Morrison DR, Des Rosiers L, et al. Definition of immobility in studies of thromboprophylaxis in hospitalized medical patients: a systematic review. J Vasc Nurs 2010;28:54-66.

48 Cook D, Duffett M, Lauzier F, et al. Barriers and facilitators of thromboprophylaxis for medical-surgical intensive care unit patients: a multicenter survey. J Crit Care 2014;29:471.e1-e9.

49 Dalton K, O’Brien G, O’Mahony D, et al. Computerised interventions designed to reduce potentially inappropriate prescribing in hospitalised older adults: a systematic review and meta-analysis. Age Ageing 2018;47:670-8 